\title{
Institutional development, divergence and change in the discipline of project management
}

\section{Mike Bresnen}

Published in International Journal of Project Management, 34, 2016, pp 328-338.

http://dx.doi.org/10.1016/j.ijproman.2015.03.001

\begin{abstract}
Inspired by Peter Morris's major contribution to the field of project management, this paper takes up some of the challenges facing the development of the discipline of project management which are so eloquently articulated in Reconstructing Project Management (2013). Drawing upon insights from theory and research on communities of practice, forms of knowledge production, processes of structuration and institutionalisation, it highlights the diversity and complexity in the field of project management practice, theory and research and harnesses these ideas to highlight the opportunities and tensions this diversity creates. In considering the implications for the institutionalisation of project management as a professional body of knowledge and academic discipline, the argument is developed that there is not only great value to be gained by pursuing these lines of enquiry further, but also that there it is important to acknowledge diversity within the field and encourage criticality in perspective.
\end{abstract}

\section{Keywords}

Project management, knowledge, discipline, profession, practice, institutional theory, structuration theory 


\section{Institutional development, divergence and change in the discipline of project management}

\section{Introduction}

Through his seminal contributions to the field of project management theory and practice, Peter Morris has had a profound effect not only upon the generation of knowledge of importance to the development of the discipline, but also upon its continuing institutionalization in a professional body of knowledge and infrastructure of supporting practices and organizational arrangements. Not least of these are his many contributions to the work of the Association for Project Management (APM) and to this journal in which this Festschrift appears.

Peter's very early and systematic approach to unravelling the complex relationship between the unfolding logic of project tasks and the extant institutional arrangements established for the governance of construction projects (Morris, 1973) was a significant influence on this author's own early work. More than that, however, it still resonates with contemporary challenges faced in furthering the institutionalization of project management as a professional body of knowledge and academic discipline. Indeed, juxtaposing how logics of action relate to their institutional context - in the case, with regard to the discipline of project management itself continues to be a fundamental issue (Morris, 2013). What we know about project management and organization is shaped by a huge variety of actors and institutions and informed by the diverse orientations and interests that they represent. Not only does this diversity exist across 
the many disciplines and domains of practice that are interested in, and contribute towards, project management; it is also found in the many different 'recipes' for research and practice associated with different schools of thought within project management itself (Morris, 2013: 110-1). Examining these differences and understanding their effects on the development of the practice and discipline of project management is therefore both timely and important. This is even more so perhaps given the recognition through Peter's work of the breadth of application and relevance of project thinking (Morris, 1994) as well as the specificity of knowledge and depth of analysis required in furtherance of project performance (Morris, 1987).

Elsewhere, it has been argued that there are important epistemic differences between the ways in which we develop our understandings of, on the one hand, project management and organization and, on the other, organizational processes of knowledge management, learning and change (Bresnen 2006). Together these differences are reflected in the challenge of reconciling the project and the organization as competing units of analysis in the pursuit of knowledge about project management and organization. Symptomatic of these differences too perhaps are the challenges in situating project management as a self-contained discipline within mainstream business and engineering schools or in the many related disciplines (ranging from computer science to biotechnology to arts and the media) in which project management plays an inevitable and vitally important part. As someone who also occasionally straddles the communities of scholars engaged in project based research in business and construction or engineering schools, this author has a particular personal interest in what this all means for the 
sense of (professional) identity associated with being a project management researcher (cf Muzio et al, 2013).

At one level, it could be presumed that such diversity means that the development of a project management body of knowledge - in attempting to blend the domains of theory and practice, in particular - is characteristic of a more problem-focused and heterogeneously organized form of knowledge production. At the same time, however, it is clear that the continuing search for a coherent body of knowledge that codifies what we know about (and what we should know about) project organization and management - reflected, for example, in debates about PMBOK (e.g. Hodgson and Cicmil, 2007) - represents a search for a set of professional codes and practices that is more redolent of a more disciplinary-based and homogenously organized form of knowledge production.

The tensions implied in this dual orientation echo those surfaced in a long-standing distinction in science and policy studies between what are referred to as distinct 'modes' of knowledge production (Gibbons et al, 1994; Nowotny et al, 2001). According to proponents of this view, scientific research has generally shifted over time towards a more practically driven and diversely organised system of knowledge production (they label this 'Mode 2') and away from one that was traditionally more academically oriented and organised (they label this 'Mode 1'). The distinction is explored further later and, while these categorizations are of course very broad and, as will be seen, also highly contentious (Bresnen and Burrell, 2013), it is argued in this paper that they nevertheless provide a useful heuristic for understanding and exploring the 
many tensions and contradictions that still make the search for the institutionalization of project management knowledge a continuing challenge and project in its own right. In particular, that they can be used to help highlight and explore the tensions and paradoxes of institutional development and change (cf Seo and Creed, 2002) that have been connected with the emergence of the discipline and which are associated with the interplay of diverse logics of action (PMBOK $\vee$ MOP, theory $v$ practice, mainstream $v$ critical, etc).

Without the substantial platform represented by Peter's enormous contribution to the development of the discipline and the 'institutional entrepreneurship' (Maguire et al, 2004) and 'institutional work' that it represents (cf. Suddaby and Viale, 2011), such an exercise would be inconceivable. However, this paper argues that there is still plenty of space left for researchers to rise to the many challenges recently flagged up by Peter (and by others) in understanding the obstacles that still remain to the further development and institutionalization of the discipline.

\section{Effacing or embracing diversity in practice and perspective?}

In his recently published book, Reconstructing project management (2013), Peter Morris charts how project management as a practice and as a discipline has developed enormously in the last several decades, from a largely intuitive set of skills to a highly popular management discipline. Although it is now associated with a reasonably well established and institutionalised body of knowledge (associated with the PMI's project management book of knowledge (PMBOK) and alternatives, such as the APM book of knowledge), he argues that there remain many 
challenges ahead in forging a common and workable collective understanding about the nature of project management, its techniques and skills that not only combines the rigour associated with being built upon a solid corpus of academic thinking and research, but also the relevance that comes from being directly driven by practitioner needs and concerns (cf. Pettigrew, 2001). As he neatly puts it:

“... project management as a discipline is neither yet reliable enough nor engaged enough in improving its clients' performance" (Morris, 2013: 270)

Principal amongst these challenges and the central theme of Peter Morris's work is getting across the core idea that it is vital to take a Management of Projects (MOP) approach that emphasises the importance of taking the project as the focus and unit of analysis and which places emphasis on front-end project definition, the importance of the sponsor and project leadership and a more strategic approach to the management of stakeholders and externalities. Learning the techniques and procedures of project management are important, of course. But they represent a level of tactical and operational detail that is below that of the more strategic orientation which, according to Morris, is needed for the effective management of projects.

In many ways, the debate generated by this difference in orientation between MOP and PMBOK approaches represents a continuing 'hearts and minds' battle for a shared collective understanding of the nature and purpose of project management which can be distilled in the skills required of, and practiced by, project managers. Whatever one's position within this 
debate, it is clear however that the challenge of reaching any shared understanding and institutionalisation of the discipline of PM is obviously made considerably more difficult by the differentiation and diversity that is found in the practices of project management and in its multi-disciplinary knowledge base.

Project management as a practice encompasses a wide range of highly distinct and differentiated settings, including inter alia engineering and construction, IT, aerospace, R\&D, film-making, the creative arts, biomedicine, advertising, consultancy and academic research (Morris, 1994). Moreover, many of these domains of practice are not only quite distinct in terms of their fundamental tasks and goals, they also often have their own distinct institutional structures, value systems and practices that shape and influence perceptions of what is acceptable and required project management knowledge. As Morris himself concedes:

“... there have to be doubts as to whether prescriptive, normative guidance can validly be formulated and mandated for such a large, complex area of practice" (Morris, 2013: 232-3)

Fragmented institutional contexts for the 'production' of knowledge mirror these differences in practice and add greatly to the heterogeneity and complexity of the domain. Project management knowledge is not only something that has been driven considerably by diffuse developments in practice, it has also emerged, developed and been nurtured within very different academic/research contexts, including construction management and engineering 
departments, business and management schools, social science and IT/computing departments and various others besides (e.g. the performing arts and media studies). While this heterogeneity is not necessarily of itself a fundamental barrier to the sharing of knowledge, the different orientations to knowledge production and use it is associated with (theoretical/applied, mainstream/critical, etc), as well as quite distinct epistemic practices (Knorr-Cetina, 1999) and varying institutional imperatives and logics of action (Lounsbury, 2007) inevitably means that project management knowledge is seen in somewhat different ways and used for slightly different purposes.

Whereas the object of study (project management) may therefore provide a strong unifying influence, the domain of knowledge and practice it relates to is clearly highly differentiated and fragmented. Even within the established knowledge base of the discipline itself, there is enormous variation. Views vary on exactly how many schools of thought characterise the development of the discipline: Morris suggests 10 whereas others present alternative chronological accounts highlighting somewhat different stages of development (Bredillet et al, 2007; Söderlund, 2002). However, it is clear that the subject matter varies enormously ranging from early, more engineering based approaches to planning and control; to work that has been driven more by business and operations management concerns; to work that has been more influenced by critical social science thinking or driven by developments in information and communication technology. Moreover, whether these disparate approaches can be considered paradigmatically commensurate or incommensurate (and there must be 
doubts about the former in some cases), they do continue to shape thinking in different ways about what could and should constitute project management knowledge. As Morris suggests:

"What's missing - where we have difficulty and lack institutional agreement - are ways of combining and deploying the elements of this knowledge in ways that overall are optimal to the challenge presented by the project, or program, in its context" (Morris, 2013: 109)

Particular formulations - such as PMBOK - that attempt to distil project management thinking and practice into codified systems of knowledge that have institutional support and which are intended to introduce some degree of professional closure based upon credentialism (Abbott, 1988; Larson, 1977; Murphy, 1988) may have some widespread appeal and impact, but also come in for particular critical attention (Hodgson and Cicmil, 2007). However, it is clear too that there are many fundamental barriers that make the development of any such unitary and coherent knowledge base a particular challenge.

But is this not inevitable and is it necessarily such a bad thing? Given the above, it is hard to conceive of the community of practitioners and academic researchers interested in project organisation and management as ever being one coherent community of practice, with common goals and ways of making sense of project management (cf. Wenger, 1998; Brown and Duguid, 2001). Instead, it is easier perhaps to think of the terrain of project management as being occupied by multiple communities and networks of practice, each with their own 
particular perspectives and set of narratives based on distinct paradigmatic positions, epistemic practices and accepted forms of representation and articulation (Boland and Tenkasi, 1995; Lindkvist, 2005). There are quite clear differences for example, between perspectives on project management in the IT field (where, for example, Agile thinking is prominent) and perspectives in other domains of practice, such as engineering and construction. Similarly, critical thinking about projects (e.g. Hodgson and Cicmil, 2006) is quite distinct in its aims and orientation from more mainstream managerial perspectives found, for example, in the operations management domain (e.g. Maylor, 2002). Moreover, while opportunities for interaction between members of such distinct communities of practice may well occur (e.g. via academic conferences, industry-led research or government policy initiatives), these are likely to be far less common and rather more ephemeral perhaps than the formative experiences that professionals (both academic and practitioner) have through continuing professional engagement and interaction with their peers and their clientele.

In this framing of the challenge of knowledge development, diffusion and/or integration, it is important to consider too the very different ways in which these different communities develop and sustain and change their practices from one generation to the next (Lave and Wenger, 1991). What this means for the generation of knowledge about project management theory and practice is that it suggest very different 'rites of passage' associated with the institutional requirements and professional norms facing those moving into and through distinct professional communities of practice that are bound to lead to different perspectives on the disciplinary nature of project management. This may not necessarily result in divergent 
preferred outcomes when it comes to 'knowledge generation' (improving project management performance can still provide a touchstone for vastly different research undertakings). However, it is very likely to engender highly divergent 'cause-effect beliefs' (Thompson, 1967). What it also means is that there are likely to be a wide range of factors and conditions related to the constitution and development of quite distinct communities of practice that will, variously, encourage or discourage the strengthening, continuation or breaking down of barriers to knowledge sharing between them.

The translation of knowledge necessary to enable communication and knowledge sharing between such communities of practice may be partly down to the need for a common lexicon and syntax associated with project management that enables those different communities to communicate with one another (Carlile, 2002). At the level of talking about key project management phenomena, this is perhaps not too much of a problem (although experts in language and semiotics will be quick to point out that language is certainly not neutral). However, translation also involves establishing shared meaning and understandings and this is where major difficulties can arise. According to Boland and Tenkasi (1995) and others (e.g. Carlile, 2004), boundary objects, such as shared models, maps, narratives and classification schemes can here play an important part in bridging the gap between communities of practice. Boundary objects have 'interpretative flexibility'. This means that they are: 
“... plastic enough to adapt to local needs and the constraints of the several parties employing them, yet robust enough to maintain a common identity across sites ... They have different meanings in different social worlds but their structure is common enough to more than one world to make them recognisable, a means of translation" (Star \& Griesemer, 1989: 404)

The challenge here is developing a body of knowledge that is sufficiently accepted and valued as a means of bridging understanding within and between academic and practitioner communities of practice. Arguably, bodies of knowledge associated with PMBOK and MOP both strive to achieve this. However, any collectively-developed body of knowledge which is intended to be a definitive, all-encompassing representation of the knowledge base of a discipline will inevitably tend to downplay the socially constructed and perhaps contested nature of such recipes for action once social and institutional influences are taken into account (cf. Berger and Luckmann, 1967). Is the resultant knowledge base captured in PMBOK, for example, likely to be a purely objective distillation of a universally agreed set of practices? Or, is it to some extent the result of choices made that have involved some judgement and negotiated interaction amongst the large and diverse group of contributors, assessors, editors and other actors involved?

Moreover, how are choices made amongst competing conceptions of management theory and practice? While one might accept that specific practices may be situationally contingent (applied differently in different kinds of projects), this does not necessarily mean that the 
fundamentals of that knowledge base have an undisputed heritage. There are very different views on HRM practices, for example, depending on whether their underlying logic represents a so-called 'hard' (cost accounting) or 'soft' (staff development) orientation to HRM (Marchington and Wilkinson, 2012: chapter 1). Furthermore, as with any codified system of management knowledge, the more comprehensive it appears to be, the more it risks introducing distortions, insofar as it tries to codify and make explicit what is inherently tacit in nature (Tsoukas, 1996). What is meant by 'leadership skills' is perhaps a good example of the type of knowledge that is actually very hard to pin down both in theory and in practice due to its socially constituted nature (Bresnen, 1995; Western, 2008).

Whether or not one's position on project management is that it needs to be less 'execution' focused and more 'strategic', the issues and concerns above raise the question as to whether producing a fully codified, unified knowledge base about project management can ever be an entirely successful project in its own right. These issues and concerns amplify important points already made by those critical of existing attempts to align the professionalization of project management with a particular sort of knowledge base (e.g. Hodgson and Cicmil, 2007). However, they also suggest a further important question of whether any such body of knowledge (including, but not restricted to, PMBOK) has the plasticity and traction needed to act as a boundary object that can effectively form a bridge between many of those distinct communities (or schools of thought) populating the field. It could be argued instead, for example, that, in some respects, particular formulations of knowledge simply sharpen differences in understanding - not only between different domains of project practice but 
particularly perhaps between theory and practice or between mainstream and more peripheral perspectives.

The paradox here is that, not only are there institutional hurdles to be overcome to enable alternative perspectives such as MOP to perform that boundary object role instead; should it be successfully received as such, it inevitably means that it will translate only partially to other 'thought worlds' (Dougherty 1992) in other paradigmatically distinct communities of practice. Even more challenging perhaps, and following Karl Weick's important reminder of Alfred Korzybski's epigram that 'the map is not the territory', either body of knowledge (PMBOK or MOP) may enable improved sense-making and knowledge diffusion concerning project management practice, but without itself necessarily constituting that terrain. Again, we are back to the importance of meaning and the idea that any discourse of project management will inevitably be located within a web of meaning that privileges certain ontological and epistemological understandings while dismissing others (Weick, 1995; Foucault, 1980).

\section{Transforming knowledge and practice?}

The transformation of collective knowledge, understanding and practice about project management is of course an even more ambitious objective than simply enabling improved translation (Carlile, 2004). It involves attempting to transcend different perspectives and interests in our knowledge and understanding of project management: 
"There is method behind the application of mop $/ p^{3} \mathrm{~m}$, but there needs additionally to be understanding in some depth of the different disciplines and knowledge domains that are called on in creating and delivering projects and programmes effectively. The ensemble needs to be applied in an ordered way ... to create new, interdisciplinary ways of thinking" (Morris, 2013: 247-8)

Such a shift in thinking resonates with long standing debates within business and management studies about the changing nature of 'knowledge production'. An important touchstone for these debates was the thesis proposed by science policy researchers in the 1990s (Gibbons et al, 1994; Nowotny et al, 2001, 2003) that what we have been witnessing in scientific research has been a fundamental shift from a more disciplinary-based 'Mode 1' form of knowledge production to a new, more applied form of knowledge production which they labelled 'Mode $2^{\prime}$. The characteristics of these two forms of knowledge production are summarised in Table 1 below and full descriptions that highlight the more problem-focused, trans-disciplinary, and organisationally distributed knowledge processes involved in Mode 2 can be found elsewhere (Bresnen and Burrell, 2013).

\section{TABLE 1 ABOUT HERE}

The thesis has not been without its critics and a good deal of critical attention has been directed towards: the lack of underpinning empirical support for the transition to Mode 2 research in practice (e.g. Mitev and Venters, 2009); major question marks over its conceptual 
coherence and, in particular, the notion of trans-disciplinarity (Ziman 2000); and the normative underpinnings of the approach in promoting certain types of research as more 'useful' than others (Learmonth, 2012). Many have also suggested that Mode 1 knowledge production is no less important for driving and guiding contemporary academic research (Bartunek, 2007; Hodgkinson and Starkey, 2011: 360); and that the supposedly greater flexibility afforded by 'post-academic science' is something of a myth, given the institutional pressures on researchers to follow 'acceptable' lines of enquiry and to conform to highly formalised regulatory processes (Ziman, 2000: 80-1).

However, there has been persistent support for the central idea that research needs to be more problem-focused, action-oriented, cross-disciplinary and inter-organisational (Hessels and van Lente, 2008; Thorpe et al, 2011) and the thesis resonates very strongly with widespread calls within the business and management academy for combining rigour and relevance in management research (Huff, 2000; Bartunek, 2007; Pettigrew, 2001). Having said that, while there is certainly clear recognition of the value and feasibility of combining relevance and rigour in research, there is still some debate that relates to the difficulties often encountered in simultaneously trying to combine the two in practice and in determining therefore what constitutes 'useful' research (e.g. Kieser and Leiner, 2009; Learmonth et al, 2012). Recognising the quandary created through juxtaposing Mode 1 and Mode 2 forms of research in particular in this antagonistic and dualistic (duellistic?) way, some have suggested refining the idea to recognise more hybrid forms of knowledge production - that may be more driven by wider societal than narrower commercial interests (Huff and Huff, 2001). Others have even been led 
to express concerns about the 'infatuation' with the idea of Mode 2 and the need to break free of its 'stranglehold' on the debate it has provoked (Hodgkinson and Starkey, 2011; Thorpe et al , 2011).

The paradox here for project management is not that there is a need for relevant research: project management thinking has long been driven by practitioner needs and concerns and shaped by practical demands and practitioner experience. As such, some of the basic requirements for a shift to Mode 2 have been met. What is most pressing is the need to ensure that practical developments are properly supported and augmented by rigorous academic research and for the resultant project management knowledge base to be one that is commonly accepted and regarded as sufficient to provide the foundations for consolidation of the discipline:

"... in interpreting and guiding such developments ... the project management (mop) academic community has a distinctive contribution, providing sound knowledge and scholarly thinking" (Morris, 2013: 276)

However, achieving this also suggests a trans-disciplinary synthesis of the disparate academic thinking across those various communities of practice engaged in project management research. 
The challenge here is two-fold. First, the relevant academic community is, as already noted, much more pluralist than can perhaps be inferred from the above quotation and certainly more so than many other established disciplines. Different epistemic practices (between, say, those from science and humanities backgrounds or those adopting quantitative and qualitative methodologies) will inevitably mean that achieving a unitary conception of what constitutes sound knowledge is no mean achievement. Second, the process of integrating knowledge or transcending differences in this way may significantly detract from a primary focus on applying knowledge to practice through clear-cut practical recommendations. In other words, the project management discipline is in the horns of a dilemma: it arguably needs to continue to develop stronger and more widely accepted knowledge credentials, but without becoming too trapped in the apparatus of Mode 1-like legitimation and without losing sight of the importance of practical application.

Indeed, in the context of the Mode 1-Mode 2 debate, Tranfield and Starkey (1998) counsel that any resultant failure to grapple with these dilemmas might induce greater polarisation associated with the dual perils of 'academic fundamentalism' and 'epistemic drift'. The tensions created are not easily resolvable: the challenge is in managing those tensions in ways that enable the effective cross-fertilisation of ideas and learning and thus help drive the coevolution of project management thinking and practice. But for this to occur, we need to have a better understanding not only of the institutional factors and pressures enabling and inhibiting the development of the discipline, but also perhaps of how to understand better those institutional contextual influences. 


\section{Institutionalising new thinking about project management?}

This section turns to the question of how we might attempt to better understand those institutional contextual influences, building upon the suggestion by Peter Morris that we need to leverage the promise and insights of institutional theory, structuration theory and the like to better understand the challenges to developing and institutionalising project management as a discipline (Morris, 2013: 273).

Such a suggestion is not only extremely helpful but also extremely timely as institutional theory, in particular, has become a dominant influence in contemporary organisational theory particularly in the US business and management academy (Greenwood et al, 2008, Lawrence et al, 2011). In turn, its theoretical underpinnings owe a lot to the influence of structuration theory (Giddens, 1984). Both approaches grapple with the issue of how context, structure and agency interact to shape organisational action and behaviour. While not exhaustive of contemporary approaches to organisation and management (critical realism and poststructuralism are important alternative perspectives), they do offer important insights that can be harnessed to explore the development of professional domains of practice (Muzio et al, 2013).

Structuration theory (Giddens, 1984) tries to overcome the dualism of structure and agency that inevitably confuses our interpretations of the causes of behaviour in organisations by 
emphasising the recursive interplay that occurs between them. So, rather than considering behaviour as the consequence either of structure (thus determined) or agency (freewill), structuration theory treats them as a duality - in which actors' behaviour is simultaneously and continuously shaped by, and in turn re-produces (or modifies), the structural conditions in which they are embedded. Whether this leads to the reinforcement of existing structures or changes to them will depend on how rules and resources are mobilised by actors. According to structuration theory, structure consists of interpretative rules (rules of signification), which are cognitive and influence our 'sense-making' by denoting the meanings and value we attach to things; and normative rules, which are social and regulate the legitimisation of actions. Resources are also important and more structurally influenced and linked, for example, with power relationships or the control of expertise and information.

The use of structuration theory to frame empirical research is comparatively rare. However, there are some examples of research in project environments that do throw up some interesting implications. Research by Sydow and Windeler (1998), for example, has shown how harnessing rules and resources could be used to stimulate and consolidate relationships within regional inter-firm TV networks. Bresnen et al (2004), on the other hand, have applied the approach to understanding the diffusion of new management initiatives in the construction industry to find that the take up of new management practice could be significantly influenced by the attenuated links between the construction firm and distributed project management practices. In that research, individual project managers were able to mobilise quite different 
interpretive and normative rules and power resources to shape change in ways that reflected their own interests.

While such research suggests that the nature and direction of structural changes may take very different trajectories, it also shows again how competing sources of sense-making, legitimacy and power may come into play in any attempt to develop or refine a common body of knowledge and understanding about project management. If there is any modicum of 'interpretive flexibility' relating to a particular aspect of project management, then it is likely that actors within the field are likely to draw upon very diverse sets of rules and resources to make sense of and ascribe legitimacy to that particular phenomenon, with implications for its instantiation or otherwise in the corpus of project management knowledge.

In many ways, for example, the development of PMBOK can be seen as the basis for a professionalization project within project management (Larson, 1977) that has gained traction by being steered through by virtue of the power of accreditation exercised by a powerful institutional body (i.e. PMI). Whether or not that project is accepted as such depends in part upon how well that professional body of knowledge aligns with practice and makes sense to and is seen as legitimate by practitioners within the field (including academic researchers). However, it also depends on how readily it is countered by alternative or competing perspectives that are able to be mobilised by other institutional actors (e.g. APM?) who are able to draw upon appropriate power bases and equivalent rules of signification and legitimation that have similar or greater appeal (cf. Abbott, 1988). What happens will of course 
play out in a highly complex and recursive process that sees the interplay of these broader institutional forces and discourses with the enactment of more local, practical conditions of continuity and change on the ground as the 'professionalization' of project management proceeds apace.

Institutional theory or, more accurately, neo-institutional theory is not only a well established approach to organisational analysis, but also encompasses a number of diverse perspectives (Greenwood et al, 2008). Its common feature though is the core idea that organisations are not simply rationally designed, but are instead shaped by the context in which they act and through the socio-cultural legitimacy (or 'rationalised myths') they need to conform to in order to operate and survive (Meyer and Rowan, 1977). Consequently, the development of organisational forms and action within particular fields of activity (Friedland and Alford, 1991), is shaped by the distinct regulative, normative and/or cultural-cognitive context in which organisations act (Scott, 1995). So, for example, current trends in business ethics and corporate social responsibility are driven not by efficiency needs but by the benefits gained (and costs avoided) through the legitimacy that is conferred upon businesses when they conform to regulatory requirements, social obligations/expectations and shared 'taken-for-granted' understandings about how they should act.

While a good deal of the emphasis in early forms of institutional theory was on how such forces tended to promote isomorphism in structural form (DiMaggio and Powell, 1983), institutional theory has become increasingly interested in recent years in trying to understand processes of 
institutional development and change (Greenwood et al, 2008: 18-23) . Given the amount of work undertaken in this area, exploring the range of perspectives on offer and applying them to project management thinking is well beyond the scope of this paper. However, two particular approaches stand out as having particular potential relevance for attempts to develop insights into the processes of structuration, isomorphism and change associated with project management as a discipline and body of knowledge. One of these is the idea of competing 'institutional logics' (Friedland and Alford, 1991; Lounsbury, 2007); the other is the recent emphasis on 'institutional work' (Lawrence et al, 2011; Suddaby and Viale, 2011).

According to those interested in the former approach, diverse 'institutional logics' can emerge to challenge what are seen as 'legitimate' and 'taken-for-granted' structural norms and cultural values (Colyvas and Powell, 2006; Lounsbury, 2007; Reay and Hinings, 2005). While in some instances this might mean the displacement of older ways of operating, in certain contexts and, interestingly, highly networked contexts are often singled out here (Smith-Doerr, 2005) competing institutional logics may be able to co-exist and even co-mingle (Reay and Hinings, 2005). Consequently, there is likely to be a good deal of dynamic interaction between competing conceptions of what is required in a particular field and that interaction is likely to reflect the ability of different groups of actors and the interests they represent to harness sources of legitimacy in favour of either continuity or change. Across the range of perspectives in this area, Seo and Creed (2002) take a particularly interesting approach which argues that these tensions and contradictions create internal 'dialectical' forces within an institutional field that may supply an internal impetus for change (rather than change being induced by any 
external trigger or shock to the system). They highlight the driving influence of factors such as widely recognised inefficiencies and lack of adaptability of structural forms, the overelaboration of structures/processes and tendencies towards stultifying conformity. Whether or not these conditions give rise to change depends, however, upon the praxis engaged in by individuals or groups, which they define as the "active and artful exploitation of institutional conditions" (ibid: 237).

Elsewhere, this way of understanding institutional change has been applied to exploring the emergence and development of partnering in the UK construction context (Bresnen and Marshall, 2010). That analysis highlights the internal industry triggers and supporting socioeconomic conditions that enabled the status quo to be challenged and an alternative logic of action based upon collaboration rather than competition to be promoted. However, it also charts a number of other important processes. These include: the importance of key actors and agencies in being able to exercise praxis by effectively mobilising bias within existing industry structures in favour of change; the challenges of instituting a new approach in a way that could be adequately situated in very different project task and organisational circumstances (with implications for wider sector and international diffusion); and the continuing co-existing and comingling of alternative logics of action that reflect the many tensions and contradictions that still exist and which inhibit the embedding and diffusion of collaboration in contracting practice.

In many ways, the promotion of alternative conceptualisations of project management and their continuing instantiation in competing bodies of knowledge that are furthered by 
competing institutions within the field (e.g. IPMA, APM) provides a very good example of the playing out of tensions between competing institutional logics based upon the different presumptions that are made about the nature of project management knowledge. In turn, the relative strengths of each alternative lies in its power to shape not only regulatory processes (via professional accreditation) but also collective normative views and cultural-cognitive understandings of what project management is all about in ways that lends it greater legitimacy and power. Mobilising resources to exploit internal contradictions and tensions in ways that question the legitimacy of action based upon one particular logic in turn gives clues about the actions needed to attempt to exercise praxis effectively. However, the dilemma here for attempts to promote the development of an alternative project management discourse and knowledge base that can act as an accepted foundation for the discipline is, of course, that the 'artful exploitation of institutional conditions' can work both ways. Those with interests in the established way of conceptualising project management based upon a distinct logic of action and which reflects high levels of institutional investment and high levels of influence are unlikely readily to concede ground to competing perspectives that propose alternatives on the back of critiques of their frame of reference. Whether the dialectical process of institutional change depicted by Seo and Creed (2002) results in the continued co-existing of competing logics, the hegemony of one over the other or, ultimately, some sort of synthesis is a moot point. However, given that competing perspectives reflect well-established institutional and power differences and that proselytisers are promoting very different configurations of power/knowledge that could provide the foundations of the discipline (Foucault, 1980), then 
the more likely immediate and medium term consequence is, of course, considerable disagreement and friction.

The second strand of institutional theory that has some relevance resonates with the emphasis placed above on the exercise of praxis. According to those who have recently highlighted the importance of 'institutional work' (e.g. Lawrence et al, 2011; Suddaby and Viale, 2011), individual agency is also important to processes of institutional continuity and change. The development of distinct and competing bodies of project management knowledge is of course testimony not only to collective endeavours in the field but also to the impact of leading figures within the field such as Peter Morris. At one level, the development of the discipline is testament to their ability, as 'institutional entrepreneurs' (Maguire et al, 2004), to contribute to the carving out and legitimising of a field of activity based upon a particular logic of action. However, the key insight from the institutional work perspective is not simply that the actions of prominent individuals can promote change (or indeed help conserve existing institutional practices); but that routine individual action by those across the field of practice is also important in continually reproducing or occasionally challenging norms, standards and practices (Lawrence et al, 2011). In other words, continuity and change are as much emergent as teleological processes. Consequently, whereas there may be opportunities to exercise praxis in the pursuit of change, there are also important constraints too - not only from the surrounding institutional context which defines what is and what is not considered legitimate; but also from the reinforcement of existing institutional practices through the active defence and passive internalisation of existing practices by actors in the field. 
The challenge of course is to be able to harness institutional tensions and contradictions in ways that effectively question taken-for-granted assumptions about the strength and legitimacy of accepted way of operating and to successfully mobilise arguments that legitimise the direction of change (Colyvas and Powell, 2006). As Morris points out:

“... we need to think carefully about standards; how fixed they are, who defined them, are they valid" (Moris, 2013: 243)

However, such a project also requires the application of deep critical thinking - not only about the key institutional factors enabling and inhibiting change, but also about the mechanisms through which disciplinary practices continue to fuel particular established configurations of power/knowledge (Foucault, 1980). It also requires a good deal of thought about the impact of agency and, in particular perhaps, the agency of those operating in the realm of professional practice - where conceptions of project management are either internalised or not, as the case may be. In other words, institutionalising new thinking about project management not only requires action to promote change in relations within and between major institutions in the field, it also requires, at the level of professional practice, consideration of how those changes feed into the encouragement or questioning of normalised conceptions of what it means to both conduct research in, and to practice, project management (Hodgson, 2002).

\section{Concluding discussion}


None of the above should be taken to mean that the project of further establishing and consolidating the discipline and knowledge base of project management is by any means impossible. But it does suggest that there are immense difficulties and challenges that lie ahead. Not least of these are due to the high levels of differentiation and fragmentation that characterise the field of project management practice and the institutional terrain in which it sits.

However, the discussion has tried to build not only upon the firm foundations provided by Peter Morris's work, but also the strong suggestion he makes that the challenges of change might be better met if the insights of approaches such as structuration theory and institutional theory are able to be harnessed more effectively. This paper has attempted to start to do just that. However, this has not only been done with a view to identifying potential solutions and strategies for enabling change to happen (as important as these are), but also to demonstrate the tensions, contradictions and paradoxes that are thrown up when one pursues any deep critical analysis that relies upon such perspectives.

In particular, the discussion has highlighted several structural/cultural and institutional forces that tend to promote divergence as much as convergence in thinking about project management. These include: very different ways of thinking across distinct communities of practice about project management; the difficulty in establishing a project management body of knowledge that effectively acts as a boundary object and bridges communities of practice; 
the challenges and limitations of developing an inter-disciplinary approach based upon producing trans-disciplinary knowledge about project management; the fragmentation in structures and epistemic cultures that help to actively reinforce fragmentation and segmentation of knowledge; and the tensions and contradictions that can inhibit attempts to promote alternative discourses of project management.

A focus on structural constraints of course downplays agency and a theme that has threaded through the above discussion has been the complex relationships between agency and structure in the promulgation of project management knowledge and practice. In many ways, the development of the discipline that Morris (2013) charts so well has proceeded from what Blackler (1995) might classify as more embodied and 'embrained' forms of practical knowledge (based respectively on key competences and analytical skills); to more embedded and 'encultured' forms of knowledge (captured, respectively, in established processes and procedures and shared collective understandings). The challenges of reconciling structure and agency are also apparent in the ways in which researchers and practitioners might engage in their respective communities of practice, apply and develop epistemic practices within their particular field and respond to institutional imperatives and constraints.

The theme of agency and structure is also important however in thinking through the implications for promoting change. As Morris suggests,

“Actors - us: people - can act and make a difference" (Morris 2013: 247) 
While this is certainly the case, the foregoing discussion has suggested that there are a number of important points to emphasise in relation to this. First, that actors are inevitably embedded in and constrained by their own institutional structures and, following Giddens (1984), their actions may not only help shape change, but also may simply reproduce the structural assumptions of the context in which they are embedded. Consequently, efforts to champion change not only need to have an awareness of the opportunities for change that can be harnessed by exploiting institutional contradictions and paradoxes, but also the very subtle ways in which actions taken may have unintentional consequences in reinforcing barriers to that change. For example, the insistence on evidence-based decision-making in the medical domain is all very well and good; but it unintentionally creates barriers to solving medical problems that need urgent attention or for which there is no readily available evidence. The need therefore is for some reflexivity in approach combined with a critical awareness of how our actions relate to our context.

Second, the foregoing has suggested that there may certainly be a need for a good deal of praxis and further 'institutional work' (Suddaby and Viale, 2011) in challenging and changing existing preconceptions of the nature of project management. In surfacing issues of interests and power, the discussion has also alluded to the inherently political nature of the process. However, it has also suggested that institutional work is something that is continually engaged in as existing practices are enacted and therefore reproduced and reinforced. Consequently, it becomes important to understand the ways in which alternative conceptions of project 
management are internalised and accepted by practitioners actively engaged in applying and furthering the discipline in the field. Without this, there is a danger that any formulation - not simply one such as PMBOK that is highly codified - becomes reified and abstracted from everyday practical experience. Moreover, it is as important perhaps to note that the actions required are as much symbolic and linguistic insofar as they represent attempts actively to shape discourse about the nature and meaning of project management as a discipline and domain of practice. The saying goes that 'actions speak louder than words'. But in the realm of discourse, linguistic constructions and their symbolic resonances will have very powerful effects on what is considered legitimate or illegitimate thought and action (Lukes, 1974, Foucault, 1980). At very least they constitute part of a powerful armoury that can be used to promulgate or resist change.

Above all, what the foregoing should be taken to suggest is that the development of new thinking about project management would benefit not from approaches that encourage closure around a tightly defined and codified body of knowledge (indeed, this is a major critique of the PMBOK approach). What is needed instead is an approach that is still convergent in its aims, but more open to divergent influences and which recognises and celebrates the diversity in perspective and difference in context that exists. Particularly important here, it is argued, is the value that can be derived from a more critical and reflexive take on understanding processes of professionalization and institutionalisation associated with the development of project management as a body of knowledge, professional practice and academic discipline. 
Drawing upon elements of situated learning theory, structuration theory and neo-institutional theory, that is what this paper has set out to do. It has also alluded to insights from poststructuralism and the linguistic turn in social theory to make the case and hinted at other critical perspectives (such as critical realism) that also have a great deal to offer. In doing so, it has intentionally drawn upon a wide range of alternative perspectives on the issue, with the aim of opening up some new and very different avenues of research for exploring relationships between institutional change, the development of project management as a discipline and the professionalization of project management practice.

\section{An agenda for future research?}

As such, there are a number of questions that emerge from the foregoing discussion that can be considered as an agenda for future research into the factors and processes influencing the development of the discipline. These relate to the nature of project management knowledge itself, the diverse communities of practice to which it relates, and the processes of structuration and institutionalisation associated with professionalization and the development of the discipline.

First, in what ways do different forms of knowledge about project management aim to meet the dual requirements of rigour and relevance and how is that traced back to the epistemological foundations of that knowledge base and the institutional structures that have generated and nutured it? How well in fact do highly codified systems of knowledge (such as 
PMBOK) translate into practice across the very diverse fields of application to which they are meant to apply? How far do they in turn allow the sublimation of practical knowledge into that evolving knowledge base from practices spread across those activity domains? To what extent is the knowledge base of project management reified and abstracted or internalised and grounded in practice?

Second, where are the main points of contact, overlaps and gaps between the various communities of practice and institutional bodies populating the wider terrain of project management theoretical development and/or practical application? Where are the sites of contested professional terrain and where are the 'structural holes' (Burt, 1992) in networks of interaction? What factors tend to enable and inhibit flows of knowledge and learning within and between these communities of practice and what part do boundary conditions and objects play? How do different communities of practice that are engaged in project management socialise members of their community into understanding project management and how does this encourage convergence or divergence in perspective?

Third, how has the development of project management as a knowledge base and discipline been shaped by the sense-making, legitimation and power dynamics associated with structuration processes and attempts at institutionalisation and professional closure? What are the meaning-making strategies, legitimating devices and power resources that have been drawn upon (and are still deployed) to promulgate particular versions of project management as a knowledge base and discipline? How are those strategies, devices and resources viewed 
and responded to across the different domains of project management activity and how do they relate to professional practice in the field? What institutional factors and forces promote the reproduction and reinforcement of current ways of thinking about project management and what factors and forces open up options for change based upon the surfacing of tensions, contradictions and paradoxes? What opportunites are open to actors to exercise praxis to promote change and what types of 'institutional work' enable or inhibit change?.

These questions are intended to build constructively upon the platform provided by Peter Morris's recent suggestions concerning the challenges still facing the development of the discipline. Without the fundamental contribution that Peter has made to help establish the foundations for the academic development of the field of project management, such an analysis would have been much more difficult to legitimise and may even have proved impossible to develop. It is a testament to the breadth and depth of his contribution to the field and its impact amongst academics and practitioners that such an exercise is now not only possible to legitimate, it is also in this author's view arguably both desirable and essential.

\section{References}

Abbott, A. 1988 The system of professions: an essay on the division of expert labour. Chicago, IL: University of Chicago Press. 
Bartunek, J. M. 2007 Academic-practitioner collaboration need not require joint or relevant research: Toward a relational scholarship of integration. Academy of Management Journal, 50(6), 1323-1333.

Berger, T. and Luckmann, P. 1967 The social construction of reality. New York: Doubleday Anchor.

Blackler, F. 1995 Knowledge, knowledge work and organisations: an overview and interpretation. Organisation Studies, 16 (6), 1021-46.

Boland, R. J. and Tenkasi, R. V. 1995 Perspective making and perspective taking in communities of knowing. Organization Science, 6 (4), 350-72.

Bredillet, C., Anbari, F. and Turner, J. R. 2007 Exploring research in project management: nine schools of project management research. Project Management Journal, 27(4).

Bresnen, M. 1995 All things to all people? Perceptions, attributions and constructions of leadership. Leadership Quarterly, 6 (4), 495-513.

Bresnen, M. (2006) Conflicting and conflated discourses? Project management, organisational change and learning. In D. Hodgson and S. Cicmil (eds), Making Projects Critical, pp. 68-89. Basingstoke: Palgrave Macmillan. 
Bresnen, M. and Burrell, G. (2013) Journals à la mode? Twenty years of living alongside Mode 2 and the new production of knowledge. Organisation, 20(1), 25-37.

Bresnen, M., Goussevskaia, A. and Swan, J. 2004 Embedding new management knowledge in project-based organisations. Organization Studies, 25(9), 1535-55.

Bresnen, M. and Marshall, N. (2010) Projects and partnerships: institutional processes and emergent practices. In P. Morris, J. Pinto and J. Söderlund (eds) OUP Handbook of Project Management, pp. 154-174, Oxford: Oxford University Press.

Brown, J. S. and Duguid, P. 2001 Knowledge and organisation: a social practice perspective. Organization Science, 12, 198-213.

Burt, R. S. 1992 Structural holes: the social structure of competition. Harvard: Harvard University Press.

Carlile, P. 2002 A pragmatic view of knowledge and boundaries: Boundary objects in new product development. Organization Science, 13, 442-455. 
Carlile, P. 2004 Transferring, translating and transforming: An integrative framework for managing knowledge across boundaries. Organization Science, 15(5), 555-568.

Colyvas, J. A. and Powell, W. W. 2006 Roads to institutionalisation: The re-making of boundaries between public and private science. Research in Organisational Behaviour, 27, 305-353.

DiMaggio, P. J. and Powell, W. W. 1983 The iron cage revisited: institutional isomorphism and collective rationality in organisational fields. American Sociological Review, 48: 147-160.

Dougherty, D. 1992 Interpretive barriers to successful product innovation in large firms. Organization Science, 3, 179-202.

Foucault, M. 1980 Power/knowledge. (ed. C. Gordon). Hemel Hempstead, Harvester Wheatsheaf.

Friedland, R. and Alford, R. R. 1991 Bringing society back in: symbols, practices and institutional contradictions. In W. W. Powell and P. J. DiMaggion (eds), The new institutionalism in organisational analysis. Chicago, ILL: University of Chicago Press.

Gibbons, M., Limoges, C., Nowotny, H., Schwartzman, S., Scott, P. and Trow, M. 1994 The new production of knowledge: the dynamics of science and research in contemporary societies. London: Sage. 
Giddens, A. 1984 The constitution of society: outline of the theory of structuration. Cambridge: Polity Press.

Greenwood, R., Oliver, C., Suddaby, R. and Sahlin, K. 2008 The Sage handbook of organisational institutionalism. London: Sage.

Hessels, L. K. and van Lente, H. 2008 Re-thinking new knowledge production: A literature review and a research agenda. Research Policy, 37, 740-760.

Hodgkinson, G. P. and Starkey, K. 2011 Not simply returning to the same answer over and over again: reframing relevance. British Journal of Management, 22, 355-369.

Hodgson, D. and Cicmil, S. 2006 (eds), Making Projects Critical. Basingstoke: Palgrave Macmillan.

Hodgson, D. 2002 Disciplining the professional: the case of project management. Journal of Management Studies, 39(6), 803-21.

Hodgson, D. and Cicmil, S. 2007 The politics of standards in modern management: making 'the project;' a reality. Journal of Management Studies, 44(3), 431-50. 
Huff, A. S. 2000 Changes in organisational knowledge production. Academy of Management Review, 25(2), 288-293.

Huff, A. S. and Huff, J. O. 2001 Re-focusing the business school agenda. British Journal of Management, 12, S49-S54.

Kieser, A. and Leiner, L. 2009 Why the rigour-relevance gap in management research is unbridgeable. Journal of Management Studies, 46, 516-533.

Knorr-Cetina, K. 1999 Epistemic cultures: How the sciences make knowledge. Cambridge MA: Harvard University Press.

Larson, M. S. 1977 The rise of professionalism: a sociological analysis. Berkeley, CA: University of California Press.

Lawrence, T., Suddaby, R. and Leca, B. 2011 Institutional work: refocusing institutional studies of organisation. Journal of Management Inquiry, 20(1), 52-58.

Learmonth, M., Lockett, A. and Dowd, K. 2012 Promoting scholarship that matters: The uselessness of useful research and the usefulness of useless research. British Journal of Management, 23, 35-44. 
Lindkvist, L. 2005 Knowledge communities and knowledge collectivities: A typology of knowledge work in groups. Journal of Management Studies, 42(6), 1190-1210.

Lave, J. and Wenger, E. 1991 Situated learning: legitimate peripheral participation. Cambridge: Cambridge University Press.

Lounsbury, M. 2007 A tale of two cities: Competing logics and practice variation in the professionalizing of mutual funds. Academy of Management Journal, 50.2, 280-307.

Lukes, S. 1974 Power: A Radical View. London, Macmillan.

Maguire, S., Hardy, C. and Lawrence, T. B. 2004 Institutional entrepreneurship in emerging fields: HIV/AIDS treatment advocacy in Canada. Academy of Management Journal, 47: 657-679.

Marchington, M. and Wilkinson, A. 2012 Human resource management at work. London: CIPD.

Maylor, H. 2002 Project management ( $3^{\text {rd }}$ edn). London: Prentice Hall.

Meyer, J. W. and Rowan, B. 1977 Institutionalised organisations: formal structure as myth and ceremony. American Journal of Sociology, 83: 440-463.

Mitev, N. and Venters, W. 2009 Reflexive evaluation of an academic-industry research 
collaboration: Can mode 2 management research be achieved? Journal of Management Studies, 46(5), 733-754.

Morris, P.W.G. 1973 An organizational analysis of project management in the building industry. Building International, 6, 595-615.

Morris, P.W.G. 1994 The management of projects. London: Thomas Telford.

Morris, P.W.G. 2013 Reconstructing project management. Chichester: Wiley-Blackwell.

Morris, P.W.G. and Hough, G.H. 1987 The anatomy of major projects. Chichester: Wiley.

Murphy, R. 1988 Social closure: the theory of monopolisation and exclusion. Oxford: Clarendon.

Muzio, D., Brock, D. M. and Suddaby, R. 2013 Professions and institutional change: towards an institutionalist sociology of the professions. Journal of Management Studies, 50 (5), 699-721.

Nowotny, H., Scott, P. and Gibbons, M. 2001 Re-Thinking science: Knowledge and the public in an age of uncertainty. Cambridge: Polity.

Nowotny, H., Scott, P. \& Gibbons, M. 2003 'Mode 2' revisited: the new production of knowledge. Minerva, 41, 3, 179-194. 
Pettigrew, A.M. 2001 Management research after modernism. British Journal of Management, 12, S61-S70.

Reay, T. and Hinings, C. R. 2005 The recomposition of an organizational field: Health care in Alberta. Organization Studies, 26(3): 351-384.

Scott, W. R. 1995 Institutions and organisations. Thousand Oaks, CA: Sage.

Seo, M.G. and Creed, W.E.D. 2002 Institutional contradictions, praxis and institutional change: a dialectical perspective. Academy of Management Review, 27, 222-47.

Smith-Doerr, L. 2005 Institutionalising the network form: How life scientists legitimate work in the biotechnology industry. Sociological Forum, 20(2), 271-299.

Söderlund, J. 2002 On the development of project management research: schools of thought and critique. International Project Management Journal, 8(1), 20-31.

Star, S.L. \& Griesemer, J. 1989 Institutional ecology, translations and boundary objects: Amateurs and professionals in Berkley's Museum of Vetebrate Zoology 1907-1939. Social Studies of Science, 19(3), 387-420. 
Suddaby, R. and Viale, T. 2011 Professionals and field-level change: institutional work and the professionalization project. Current Sociology, 59, 423-41.

Sydow, J. and Windeler, A. 1998 Organising and evaluating inter-firm networks: a structurationist perspective on network processes and effectiveness. Organization Science, 9(3), 265-83.

Thompson, J.D. 1967 Organisations in action. Chicago: McGraw-Hill.

Thorpe, R., Eden, C., Bessant, J. and Ellwood, P. 2011 Rigour, relevance and reward: Introducing the knowledge translation value chain. British Journal of Management, 22, 420-431.

Tranfield, D. and Starkey, K. 1998 The nature, social organization and promotion of management research: Towards policy. British Journal of Management, 9, 341-353.

Tsoukas, H. 1996 The firm as a distributed knowledge system: a social constructivist approach. Strategic Management Journal, 17, 11-25.

Weick, K. 1995 Sensemaking in organizations. Thousand Oaks, CA: Sage.

Wenger, E. 2000 Communities of practice and social learning systems. Organization, 7 (2), 22546. 
Western, S. 2008 Leadership: a critical text. London: Sage.

Ziman, J.M. 2000 Real Science: What it is and what it means. Cambridge: Cambridge Univ.

Press. 
Table 1: Changing modes of knowledge production

Mode 1

Problems defined by academic community

Disciplinary knowledge

Homogeneity: hierarchical and stable

organisations

Research as objective

Quality control by the 'invisible college'

\section{Mode 2}

Knowledge produced in the context of

application

Trans-disciplinary knowledge

Heterogeneity: diverse, transient and flexible organisations

Research as reflexive and dialogical

New forms of quality control emphasising

social accountability

Based on: Gibbons et al (1994), Nowotny et al (2003) 